\title{
Cell growth on 3D microstructured surfaces
}

\author{
W.W.R. Araujo ${ }^{\text {a,* }}$, F.S. Teixeira ${ }^{\text {a }}$, G.N. da Silva ${ }^{\text {b }}$, D.M.F. Salvadori ${ }^{\text {c }}$, M.C. Salvadori ${ }^{\text {a }}$, I.G. Brown ${ }^{\text {d }}$ \\ a Institute of Physics, University of São Paulo, C.P. 66318, CEP 05315-970 São Paulo, SP, Brazil \\ b Pharmacy School, UFOP - Federal University of Ouro Preto, Ouro Preto, MG, Brazil \\ c Botucatu Medical School, UNESP - São Paulo State University, Botucatu, SP, Brazil \\ d Lawrence Berkeley National Laboratory, 1 Cyclotron Road, Berkeley, CA 94720, United States
}

\section{A R T I C L E I N F O}

\section{Article history:}

Received 4 November 2015

Received in revised form 29 January 2016

Accepted 7 March 2016

Available online 14 March 2016

\section{Keywords:}

Biomaterials

Surface patterning

Cell aggregation

Optical microscopy

\begin{abstract}
A B S T R A C T
Chinese Hamster Ovary (CHO) cell cultures were grown on surfaces lithographed with periodic 3D hexagonal microcavity array morphology. The range of microcavity size (inscribed circle diameter) was from $12 \mu \mathrm{m}$ to $560 \mu \mathrm{m}$. CHO cells were grown also on flat surfaces. The characterization was performed with respect to cell growth density (number of nuclei per unit area) by fluorescence optical microscopy and evaluated by correlation function analysis. We found that optimum microcavity radius was $80 \mu \mathrm{m}$, concerning to the maximum cell growth density, being even greater than the growth density on a flat (unstructured) substrate of the same material. This finding can be important for optimization of biotechnological processes and devices.
\end{abstract}

C 2016 Published by Elsevier B.V.

\section{Introduction}

The chemical and structural similarities of cells lead us to search for systematics in their architecture and components [1]. It is known that cell growth is usually anchorage dependent and requires attachment to a solid surface [2-4], and cell adhesion to biomaterials with a suitable surface is fundamental to many biotechnological processes $[5,6]$. Numerous human and veterinary use pharmaceuticals, such as human tissue plasmid activator [7,8] and viral vaccines (hepatitis [9], rabies [10], influenza [11], polio, rotavirus, food engineering [12] and mouth disease $[12,13])$ are produced by anchorage dependent cells. Geometrical and mechanical properties of the cell microenvironment have great impact on cell morphogenesis and function, and can interfere with cell cytoskeleton architecture, polarity, migration, division, growth and differentiation. Cell behavior can be regulated by interaction between neighboring cells and by interaction with the extracellular matrix (ECM) $[14,15]$. These environmental conditions are vital for homeostasis maintenance, and their deregulation can lead to loss of integrity or even cell death [16]. Thus cell growth on microstructured surfaces is an important field of investigation.

The literature reports a number of studies of cell cultures grown on surfaces modified by nano/micro-patterning of different ECM receptors in selected areas [17-24]. These studies have explored cell growth on various kinds of patterning formed by a variety of techniques, and have looked at how the cell culture responds to these features.

\footnotetext{
* Corresponding author.

E-mail addresses: wwlysses@if.usp.com (W.W.R. Araujo), mcsalva@if.usp.br (D.M.F. Salvadori).
}

However, cell growth on 3D microstructures that tend to isolate cells within 3D "microcavities" - a kind of microstructuring that differs fundamentally from the prior work - has been not reported previously. The work summarized here makes use of electron beam lithographed hexagonal microstructures as the surface morphology on which the cells are grown.

The objective of this work was investigating cell growth on chemically homogeneous microcavity patterns, monitoring the growth behavior of the cells due to morphology of the surface. The results of this work can contribute for scaffolds design [25-27] and for optimal conditions for cell growth in general sense.

\section{Materials and methods}

\subsection{Surface microfabrication}

Chinese Hamster Ovary (CHO) cells were cultured on 3D hexagonally microstructured substrates. Fluorescence optical microscopy (FOM) and correlation function analysis were used to characterize the growth. Periodic microstructures were generated on SU-8 (2005 from Micho Chem, resin used for electron beam lithography - electron resist) surfaces by electron beam lithography. The morphology was composed of hexagonal cavities; see Fig. 1, where $R$ is the radius of a circle inscribed within the hexagonal microcavity, $h$ the cavity depth and $\beta$ the wall thickness between cavities. The cavity aperture $2 R$ was varied for different substrates, with values of $12,30,80,280$ and $560 \mu \mathrm{m}$, generating samples referred to here as HEX-12, HEX-30, HEX-80, HEX-280 and HEX-560, respectively. The cavity depth $h$ was kept constant at $h=$ $3 \mu \mathrm{m}$, and the wall thickness $\beta$ varied according to the cavity cell size 
$2 R$. The parameters used for electron beam lithography were $15 \mathrm{pA}$ beam current, $0.07 \mathrm{nC} / \mathrm{cm}$ exposure dose, and $10 \mathrm{~mm}$ working distance.

\section{2. $\mathrm{CHO}$ cell growth}

The cells were stored in liquid nitrogen (freezing solution $10 \%$ DMSO) in aliquots of $1 \times 10^{6}$ cells $/ \mathrm{mL}$, and thawed and seeded in monolayers into flasks of $25 \mathrm{~cm}^{2}$ (Corning), in HAM-F10 (Invitrogen) medium supplemented with $10 \%$ fetal bovine serum (Cultilab) and antibiotics (streptomycin, $1 \%$ and penicillin $1 \%$ ). Cell cultures were incubated in humid $5 \% \mathrm{CO}_{2}$ atmosphere at $37^{\circ} \mathrm{C}$ until reaching approximately $90 \%$ confluence, when they were subcultured. At that time, the medium was removed and $5 \mathrm{~mL}$ of Hanks $1 \mathrm{X}$ solution $(0.4 \mathrm{~g} \mathrm{KCl}$, $0.06 \mathrm{~g} \mathrm{KH}_{2} \mathrm{PO}_{4}, 0.04 \mathrm{~g} \mathrm{Na}_{2} \mathrm{HPO}_{4}, 0.35 \mathrm{~g} \mathrm{NaHCO}_{3}, 1 \mathrm{~g}$ glucose, $8 \mathrm{~g} \mathrm{NaCl}$, $\mathrm{H}_{2} \mathrm{O}$ q.s.p. $1000 \mathrm{~mL}$ ) were added for $2 \mathrm{~min}$. The Hanks solution was removed and $2 \mathrm{~mL}$ of trypsin $0.25 \%$ /EDTA $1 \mathrm{X}$ (Invitrogen) were added for $5 \mathrm{~min}$, until the cells detached. Subculture was performed splinting 1 confluent culture flasks to 2 sub-confluent culture flasks (1:2 ratio) every $24 \mathrm{~h}$ in culture flasks of $25 \mathrm{~cm}^{2}$. For the studies carried out, experimental design cells were always between the $3 \mathrm{rd}$ and 5 th passages. Cell viability on the surfaces was evaluated beforehand by the trypan blue (Merck) exclusion test. The number of dead cells (apoptosis/necrosis) was about $0.7 \%$, which is not significant.

\subsection{Fluorescence optical microscopy}

After $24 \mathrm{~h}$ incubation, cells were fixed and their nuclei labeled with DAPI fluorophore as follows. The attached cells were washed three times with PBS $1 \mathrm{X} 1 \mathrm{M}$ at $37{ }^{\circ} \mathrm{C}$ and fixed using $4 \%$ paraformaldehyde for $15 \mathrm{~min}$ at room temperature (RT). Cells were permeabilized by washing three times with $0.2 \%$ Triton X100 (Sigma) in PBS for 5 min at RT. The cells were then washed again three times with PBS and stained with Prolong Gold DAPI (Life Technologies). A volume of 20 $30 \mu \mathrm{L}$ of this suspension was placed onto the substrate surface and covered with a coverslip. Samples were allowed to set in the dark, at room temperature, for $24 \mathrm{~h}$ before analysis. Nucleus morphology was observed using an epifluorescence microscope (Olympus BX 51 with U-RFL-T fluorescence module), with light source at $350 \mathrm{~nm}$ excitation wavelength and with a CCD camera (Qcolor 5) for image acquisition.

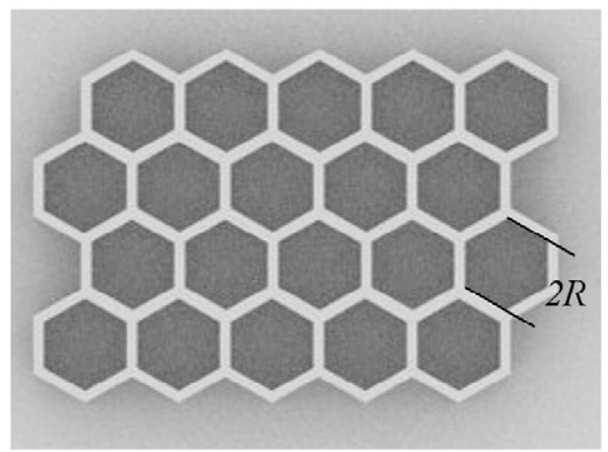

(a)

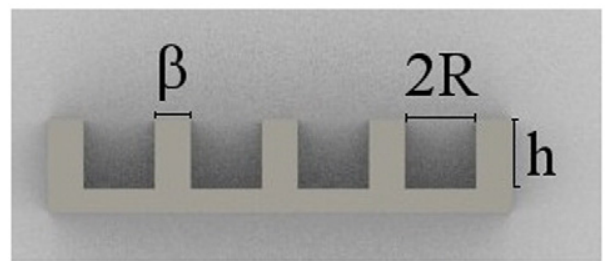

(b)

Fig. 1. Schematic of the periodic microstructures used. The morphology was composed of hexagonal cavities, shown (a) in top view, and (b) in cross-section. $R$ is the radius of the inscribed circle, $h$ the cavity depth, and $\beta$ the wall thickness between cavities.

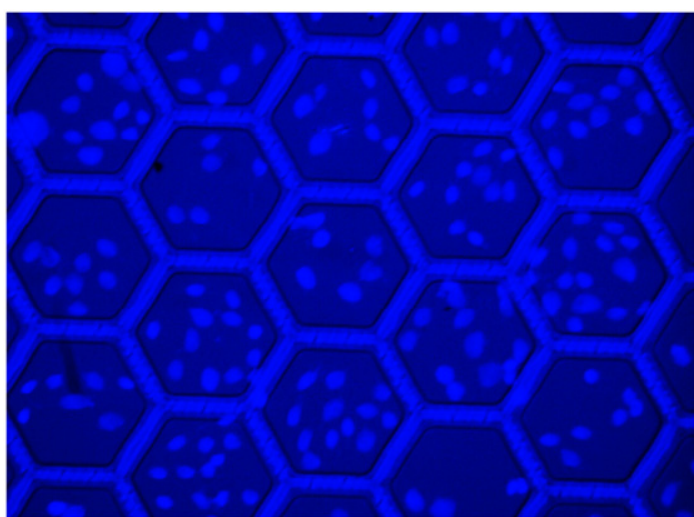

(a)

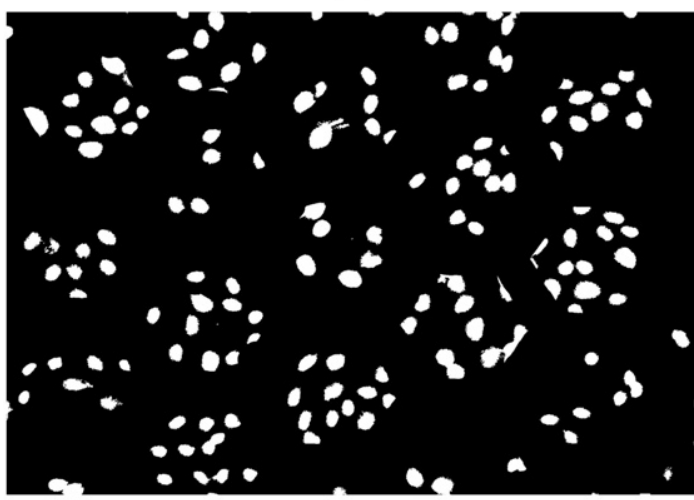

(b)

Fig. 2. Fluorescence optical microscopy images. (a) Original captured image and (b) Binarized image. The images have size of $437 \times 328 \mu \mathrm{m}^{2}$ at $0.17 \mu \mathrm{m} /$ pixel.

The nucleus of the cell was considered intact when it was glowing brightly and homogeneously; apoptotic nuclei were identified by their condensed chromatin at the periphery of the nuclear membrane or by totally fragmented nuclear bodies [28]. Cell growth was evaluated by counting the number of nuclei per unit area on each substrate.

\subsection{Image processing}

The FOM images (Fig. 2(a)) were processed by extracting the blue channel using ImageJ software [29-31] or Fiji software [32], after which the resulting images were in grayscale, allowing correlation analysis. The color of the structures was first set to the color of the background, and binarization then done. The final image was evaluated by correlation function analysis, where the white cells were associated with a " 1 " value and the black background associated with " 0 " (Fig. 2(b)).

\subsection{Statistical analysis}

For each surface pattern size was performed three identical experiments, generating groups of three samples. Normality tests for

Table 1

Parameters of the hexagonal microstructures lithographed on SU-8 as obtained by SEM and AFM measurements.

\begin{tabular}{llll}
\hline Sample & Diameter, $2 R(\mu \mathrm{m})$ & Wall thickness, $\beta(\mu \mathrm{m})$ & Height, $h(\mu \mathrm{m})$ \\
\hline HEX-12 & 12 & 1.3 & 3 \\
HEX-30 & 30 & 2.0 & 3 \\
HEX-80 & 80 & 3.5 & 3 \\
HEX-280 & 280 & 6.5 & 3 \\
HEX-560 & 560 & 9.0 & 3
\end{tabular}




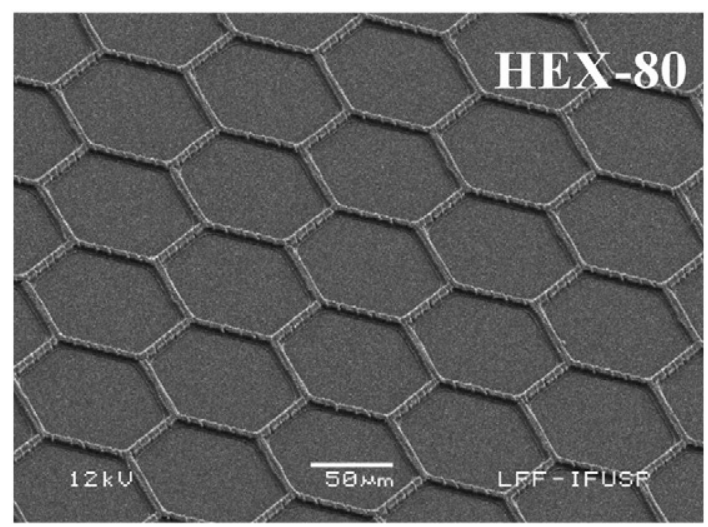

Fig. 3. SEM micrograph of the HEX- $80(2 R=80 \mu \mathrm{m})$ substrate fabricated on SU- 8 by electron beam lithography.

statistical analysis were applied for each group, using Shapiro-Wilk test [33], where any p-value below 0.1 was considered statistically significant. An unpaired $t$-test [33] was used for the statistical comparison method between the control and each samples group. The results are presented as histograms containing mean \pm standard error. Asterisks indicate significant differences between the sample groups and the flat SU-8 surface control and CI denotes the Confidence Interval.

\section{Results and discussions}

The parameters of the hexagonal microstructures were confirmed by scanning electron microscopy (SEM) and by atomic force microscopy (AFM) measurements and are summarized in Table 1. Fig. 3 shows a typical SEM micrograph of the microstructured HEX-80 substrate. Previous works describe [34-36] more details about the lithographed surface characteristics.

Cell growth density results are shown in Fig. 4(a), indicating that the greatest growth density was on HEX-80 ( $t$-test, $\mathrm{p}>0.1, \mathrm{CI}=95$ ), as confirmed in the box-plot of Fig. 4(b). Since the average size of CHO cells grown on flat SU-8 was $35 \pm 1 \mu \mathrm{m}$ (measured by conventional optical microscopy), we suggest that the reduced cell proliferation on surfaces containing periodic cavities of HEX-12 and HEX-30 can be problematic for cell adhesion because a cell can span more than a single microcavity. For HEX-80, HEX-280 and HEX-560 substrates, the cells primarily grew inside the cavities, suggesting that adherence was not adversely affected by the microstructures. We noted that the cell growth density on HEX-280 and HEX-560 was close to that for flat SU-8, as expected because the dimensions of the structures were much greater than the cell size, resembling flat substrates.

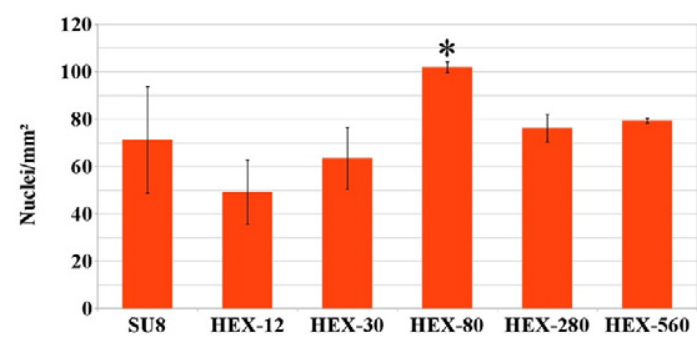

(a)

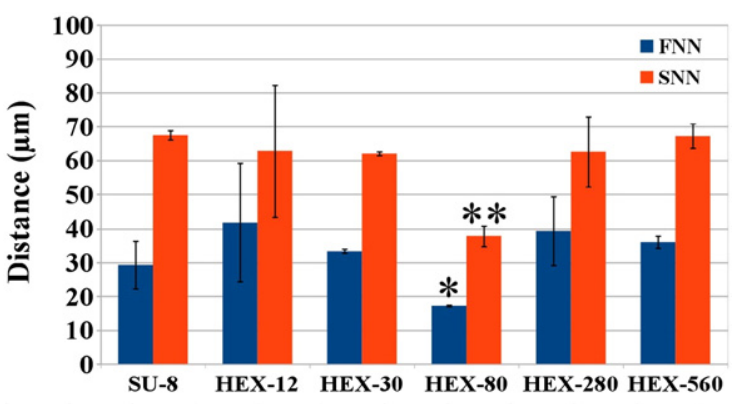

Fig. 5. Distance between first nearest-neighbor cells (FNN), and between second nearestneighbor cells (SNN). An unpaired $t$-test was used for the statistical analysis. Symbol indicating the statistical significance are placed above the histogram values ( ${ }^{*} \mathrm{p}<0.05$ ${ }^{* *} \mathrm{p}<0.001$ compare to the flat SU-8 control).

Correlation function analysis using a method based on Gompper's model [37] revealed that the distance between the first and second nearest-neighbor cells was lower for the HEX-80 substrate, i.e., the cells were closer to each other. For the other surface patterns, the analysis showed that cells were more separated. See Fig. 5. Table 2 summarizes the results for the correlation function analysis fitting parameters - the agglomerate radius $r c$, the distance between particle agglomerates $d c$, and the number of first nearest-neighbors $N p$. Table 2 includes statistic analysis using ANOVA; symbols, placed aside values, are indicating the statistical significance of similarity $\left(\mathrm{tp}<0.01,{ }^{*} \mathrm{p}>0.1,{ }^{* *} \mathrm{p}<0.05,{ }^{\circ} \mathrm{p}<0.03,{ }^{\circ} \mathrm{p}<0.05, \mathrm{CI}=95\right)$. For the flat SU-8 and HEX-80 substrates, the agglomerate radius and distance between agglomerates were the same and exhibited low values. Importantly, we point out that the number of first nearest-neighbors for HEX-80 $\left(N_{p}=15 \pm 1, t\right.$-student, $\left.\mathrm{p}<0.03, \mathrm{CI}=95\right)$ was significantly greater than for flat SU-8 $\left(N_{p}=10 \pm 2\right)$ - the cell density was greater for HEX-80 than for a flat substrate (consistent with the results given above). The HEX-12 and HEX-30 substrates displayed greater agglomerate radius and distance between agglomerates (ANOVA, $\mathrm{p}<0.004, \mathrm{CI}=$ 95) than flat SU-8, implying a lower cell density and more difficult cell growth and encouraging greater separation between cells. However, the number of nearest-neighbors was not affected, being basically the same for flat SU-8 and HEX-12 and HEX-30 substrates. For HEX-280 and HEX-560 substrates, the agglomerate radii were similar to those for HEX-12 and HEX-30 (ANOVA, $\mathrm{p}=0.5, \mathrm{CI}=95$ ) substrates. However the distance between agglomerates was smaller for HEX-280 and HEX560 than for HEX-12 and HEX-30 (ANOVA, $\mathrm{p}<0.008, \mathrm{CI}=95$ ), suggesting more difficult cell growth on HEX-12 and HEX-30. The number of first nearest-neighbors $N_{p}$ for HEX-280 and HEX-560 was similar to that for flat SU-8, HEX-12 and HEX-30, differing only for HEX-80 (ANOVA, $\mathrm{p}<0.03, \mathrm{CI}=95$ ). Thus we conclude that when the size of

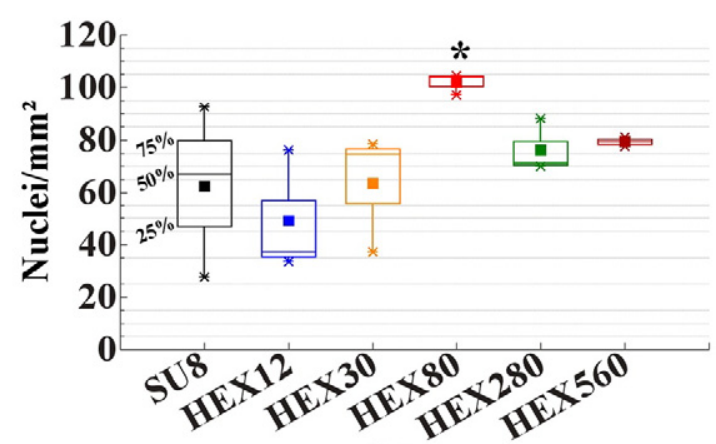

(b)

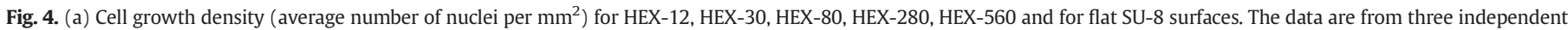

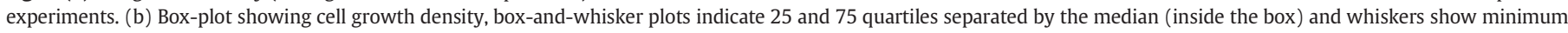

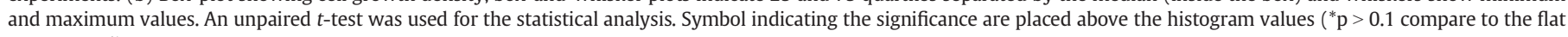
SU-8 control). 
Table 2

Results for the correlation function analysis fitting parameters: agglomerate radius $r_{c}$, distance between particle agglomerates $d_{c}$, and number of nearest-neighbors $N_{p}$. ANOVA was used for the statistical analysis for each column. Symbols indicating the statistical significance of similarity are placed aside values ( $\dagger \mathrm{p}<0.01,{ }^{*} \mathrm{p}>0.1,{ }^{* *} \mathrm{p}<0.05,{ }^{\circ} \mathrm{p}<$ $0.03,{ }^{\circ} \mathrm{p}<0.05, \mathrm{CI}=95$ ). The groups with the same symbol (or no symbol) showed no statistically significant differences between them.

\begin{tabular}{llll}
\hline Sample & $\begin{array}{l}\text { Agglomerate } \\
\text { radius, } r_{c}(\mu \mathrm{m})\end{array}$ & $\begin{array}{l}\text { Distance between } \\
\text { agglomerates, } d_{c}(\mu \mathrm{m})\end{array}$ & $\begin{array}{l}\text { Number of first } \\
\text { nearest-neighbors, } N_{p}\end{array}$ \\
\hline Flat SU-8 & $44.2 \pm 1.5 \dagger$ & $102.9 \pm 1.3^{*}$ & $10 \pm 2$ \\
HEX-12 & $51.6 \pm 0.4$ & $210.4 \pm 8.1^{* *}$ & $11 \pm 1$ \\
HEX-30 & $50.8 \pm 1.8$ & $213.7 \pm 1.4^{* *}$ & $9 \pm 1$ \\
HEX-80 & $45.9 \pm 0.3 \dagger$ & $105.7 \pm 2.4^{*}$ & $15 \pm 1^{\circ}$ \\
HEX-280 & $49.4 \pm 0.9$ & $148.4 \pm 9.5^{\circ \circ}$ & $10 \pm 1$ \\
HEX-560 & $49.4 \pm 1.7$ & $150.8 \pm 9.3^{\circ \circ}$ & $9 \pm 1$ \\
\hline
\end{tabular}

the microcavity is greater than the cell size, agglomerates tend to separate, while maintaining the number of nearest-neighbors, as occurs in the case of flat SU-8 substrate.

The correlation analysis results showed clearly what was not evidenced by merely viewing the images - that the cells on flat SU-8 had a strong tendency to form agglomerates within a radius $r_{c}$ of $45 \mu \mathrm{m}$, close to the radius of the HEX-80 $(2 R=80 \mu \mathrm{m})$ structures. Thus, the HEX-80 cavities showed the highest culture growth density performance. Supporting this superior performance of HEX-80 compared to flat SU-8 is Thery's study [14], which shows that cell cultures on patterned surfaces show similarity to physiological conditions in tissue what generates more comfortable environmental conditions. Thery argues that cells in vivo have control over the substrate properties of (1) space, which is related to the geometry of the substrate and the tissue to be formed, (2) chemical information, which is related to cell adhesion, and (3) mechanical information, which is related to the mechanical proprieties of the substrate. In cultures on flat substrates, cells lose control over the spatial property but still successfully culture because of the other substrate properties. By introducing a microarray with appropriate dimensions onto the surface, optimal conditions for cell culture growth are restored. These enhanced conditions result in the surfaces with microstructures having $2 R=80 \mu \mathrm{m}$ having the maximal cell growth density.

\section{Summary and conclusions}

We have grown cells on surfaces with 3D hexagonal microcavity array morphology, formed by electron beam lithography, over a range of microcavity sizes. These sizes ranged from much less than the cell dimension to much greater than the cell dimension. The cell growth was characterized by fluorescence optical microscopy and evaluated by correlation function analysis. The results indicated that for optimum microcavity dimension (HEX-80) - about equal to the flat surface cell agglomerate radius - the cell growth density was significantly greater than the growth density on a flat (unstructured) substrate of the same material. This finding can be important for optimization of biotechnological processes and devices.

\section{Acknowledgements}

This work was supported by the Fundação de Amparo à Pesquisa do Estado de São Paulo (FAPESP-2011/00624-9), the Conselho Nacional de Desenvolvimento Científico e Tecnológico (CNPq157021/2011-4) and the Coordenação de Aperfeiçoamento de Pessoal de Ensino Superior (CAPES-157021/2011-4), Brazil.

\section{References}

[1] D.H. Boal, Mechanics of the Cell, 2nd edition Cambridge, 2012.

[2] D.E. Discher, P. Janmey, Y. Wang, Science 310 (5751) (2005) 1139.

[3] A.P. Kourouklis, R.V. Lerum, H. Bermudez, Biomaterials 35 (17) (2014) 4827.

[4] J. Sun, D. Wei, Y. Zhu, M. Zhong, Y. Zuo, H. Fan, X. Zhang, Biomaterials 35 (17) (2014) 4759 .

[5] N. Huebsch, D.J. Mooney, Nature 462 (2009) 426

[6] A.J. García, Biomaterials 26 (36) (2005) 7525.

[7] S. Lenglet, F. Montecucco, A. Denes, G. Coutts, E. Pinteaux, F. Mach, K. Schaller, Y. Gasche, J.C. Copin, J. Cereb. Blood Flow Metab. 34 (2015) 802.

[8] K.J. Riehle, M.M. Johnson, F. Johansson, R.L. Bauer, B.J. Hayes, D.G. Gilbertson, A.C. Haran, N. Fausto, J.S. Campbell, BBA-Mol. Basis Dis. 1842 (2014) 318.

[9] A.M. Chmielewska, M. Naddeo, S. Capone, V. Ammendola, K. Hu, L. Meredith, L. Verhoye, et al., J. Virol. 88 (10) (2014) 5502.

[10] R.M. Astray, D.C. Ventini, V.L.L. Boldorini, F.G. Silva, M.P. Rocca, C.A. Pereira, Vaccine 32 (24) (2014) 2829.

[11] A.G. Posea, N.O. Morella, D.A. Matosa, E.R. Rodríguez, E.S. Rodríguez, L.R. Cordero, M.P.R. Moltó, E.M.G. Ramos, A.Á. Gutiérrez, L.G. Pérez, J.N. Gómez, A.V. Redondo, C.B. Nordelo, Biotechnol. Rep. 3 (2014) 108.

[12] Matthias Giese (Ed.) Molecular Vaccines: From Prophylaxis to Therapy, vol. 2, Springer, Vienna, 2014

[13] K. Trabelsi, A. Kamen, H. Kallel, Vaccine 32 (2014) 2808.

[14] M. Théry, J. Cell Sci. 123 (2010) 4201.

[15] K.D. Sumigray, T. Lechler, Proc. Natl. Acad. Sci. 107 (30) (2010) 13199.

[16] Q. Tseng, et al., Lab Chip 11 (2011) 2231.

[17] E. Kaivosoja, S. Myllymaa, V.-P. Kouri, K. Myllymaa, R. Lappalainen, Y.T. Konttinen, Eur. Cells Mater. 19 (2010) 147.

[18] B. Li, F. Li, K.M. Puskar, J.H.-C. Wang, J. Biomech. 42 (11) (2009) 1622.

[19] M.-F. Lai, C.-Y. Chen, C.-P. Lee, H.-T. Huang, T.-R. Ger, Z.-H. Wei, Appl. Phys. Lett. 96 (2010) 183701.

[20] F.-C. Chien, C.W. Kuo, Z.-H. Yang, D.-Y. Chueh, P. Chen, Small 7 (20) (2011) 2906.

[21] N.D. Gallant, J.R. Capadona, A.B. Frazier, D.M. Collard, A.J. Garcia, Langmuir 18 (2002) 5579.

[22] C.S. Chen, M. Mrksich, S. Huang, G.M. Whitesides, D.E. Ingber, Biotechnol. Prog. 14 (1998) 356.

[23] N. Wang, E. Ostuni, G.M. Whitesides, D.E. Ingber, Cell Motil. Cytoskeleton 52 (2) (2002) 97.

[24] D. Falconnet, G. Csucs, H.M. Grandin, M. Textor, Biomaterials 27 (2006) 3044.

[25] B.D. Smith, D.A. Grande, Nat. Rev. Rheumatol. 11 (2015) 213.

[26] S.R. Motamedian, S. Hosseinpour, M.G. Ahsaie, A. Khojasteh, World J. Stem Cells 7 (3) (2015) 657.

[27] A. Cipitria, A. Skelton, T.R. Dargaville, P.D. Daltona, D.W. Hutmacher, J. Mater. Chem. 21 (2011) 9419

[28] J.R. Eidet, L. Pasovic, R. Maria, C.J. Jackson, T.P. Utheim, Pp. 1, Diagn. Pathol. 9 (2014) 92.

[29] W.S. Rasband, J. Image, U.S. National Institutes of Health, Bethesda, Maryland, USA, http://imagej.nih.gov/ij/1997-2012.

[30] M.D. Abràmoff, P.J. Magalhães, S.J. Ram, Biophoton. Int. 11 (7) (2004) 36.

[31] C.A. Schneider, W.S. Rasband, K.W. Eliceiri, Nat. Methods 9 (7) (2012) 671.

[32] J. Schindelin, I. Arganda-Carreras, E. Frise, V. Kaynig, M. Longair, T. Pietzsch, S. Preibisch, Nat. Methods 9 (7) (2012) 676.

[33] D.M. Levine, D.F. Stephan, T.C. Krehbiel, M.L. Berenson, Statistics for Managers Using Microsoft Excel, 6th edition Pearson, 2010.

[34] M.C. Salvadori, M.R.S. Oliveira, R. Spirin, F.S. Teixeira, M. Cattani, I.G. Brown, J. Appl. Phys. 114 (2013) 174911.

[35] M.C. Salvadori, M. Cattani, M.R.S. Oliveira, F.S. Teixeira, I.G. Brown, J. Appl. Phys. 108 (2010) 024908

[36] M.C. Salvadori, M. Cattani, M.R.S. Oliveira, F.S. Teixeira, I.G. Brown, Appl. Phys. Lett. 96 (2010) 074101.

[37] G. Gompper, M. Schick, Phys. Rev. B 41 (1990) 9148. 